\title{
How Do Advantage Sectors Influence Manufacturing Competitiveness?_-An Empirical Analysis of Manufacturing Sectors in Central Six Provinces
}

\author{
Xiang Lin \\ Jianghan University, Wuhan, China
}

\begin{abstract}
Anhui, Henan, Hubei, Hunan, Jiangxi, and Shanxi are six provinces in the center of China mainland and manufacturing bases of China. By measuring some data of some manufacturing sectors in the six provinces, the author analyzed and compared the manufacturing competitiveness. These manufacturing advantage sectors in the six provinces have obvious commonality and different characteristics. The six provinces have developed a strong market competition pattern, which also indicates that the communication and cooperation of the same sectors between the provinces has greater room for win-win collaboration. Advantage sectors in these provinces mainly are resource-based sectors, which need the technological innovation to maintain the advantages of sustainable development.
\end{abstract}

Keywords: manufacturing competitiveness, advantage sectors, Hubei

\section{Introduction}

Manufacturing is the process of converting raw materials (mining products and agricultural products), components, or parts into finished goods that meet a customer's expectations or specifications. Manufacturing commonly employs a man-machine setup with division of labor in a large scale production. According to the Industrial Classification for National Economic Activities in China (GB/T 4754-2011), manufacturing contains 31 sectors which are all sectors processing of raw materials or machining and assembling of the parts in addition to mining, electricity, gas, water production and supply of thermal industry. Anhui, Henan, Hubei, Hunan, Jiangxi, and Shanxi, the six provinces in the center of China mainland have similar geographical advantages and industries allocation and development opportunities. However, compared with the other parts of China, the same manufacturing sectors compete intensely among these provinces due to the overlapped industries allocation and local protectionism, which hinder the collaboration and integration of resources. The author decides to find the advantage sectors with manufacturing competitiveness, the similarity and characteristics of these sectors and the performance of pillar cornerstone sectors in Hubei by measuring and comparing the indicators of these pillar cornerstone sectors in six provinces.

Project Supported: Jianghan University Doctoral Research Launch Funding.

Xiang Lin, doctor, associated professor, School of Business, Manufacturing Industry Development Research Center on Wuhan City Circle, Jianghan University, Wuhan, China.

Correspondence concerning this article should be addressed to Xiang Lin, No. 8 Xuefu Road, School of Business, Jianghan University, Wuhan 430056, China. 


\section{Index, Data and Model}

Regional industry or industry competitiveness is generally shaped by resource superiority, technological innovation, structural optimization, and institutional development. The industrial competitiveness theories are based on theory of absolute advantage by Smith (1776), theory of relative advantage by Ricardo (1817), theory of competitive advantage by Porter (1985). The current evaluation index systems of industrial competitiveness mainly focus on industries base or industrial output efficiency (Sun \& Du, 2010). Based on the industrial output efficiency, we establish an industrial competitiveness index and compare some indicators of manufacturing sectors of six provinces. During the establishment of index system, comprehensiveness, availability, and comparability of data are concerned. And all original data come from China Statistical Yearbook 2014 (National Bureau of Statistics of the People's Republic of China, 2015) and Statistical Yearbook 2015, 2016 of six provinces (Bureau of Statistics in six provinces, 2015; 2016).

The index system includes four indicators: market share, total asset contribution rate, main business income growth rate, and location quotient (Table 1). These independent indicators can reflect different aspects of industrial competitiveness. The indicators and the competitiveness are positively correlated. We multiply the four indicators to get an indicator of industrial competitiveness, which can help us to find the advantage sectors.

Table 1

Index System of Industrial Competitiveness

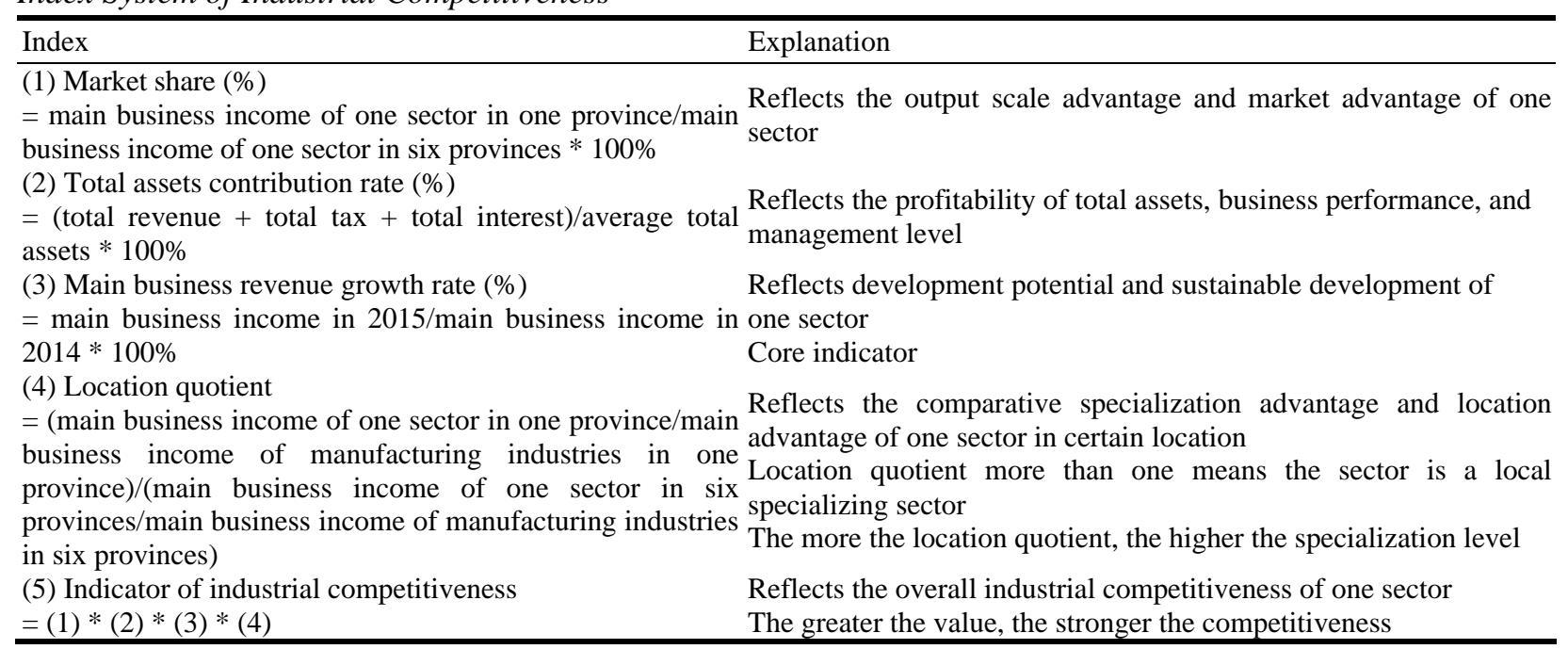

\section{Results and Discussion}

Industrial competitiveness is based on the scale of industries, so we choose the top 10 manufacturing sectors with highest business income of all manufacturing industries in Hubei and analyze the industrial competitiveness of these sectors in Hubei (Table 2). The main business income of the 10 sectors is all greater than 100 billion Chinese yuan, the total income accounts for over 70 percent of Hubei manufacturing business income in 2015. They are dominant sectors of Hubei manufacturing industries. 
Table 2

Top 10 Manufacturing Sectors in Hubei

\begin{tabular}{ll}
\hline Code & Sectors \\
\hline S1 & Motor manufacturing \\
S2 & Food processing \\
S4 & Raw chemical material and chemical products \\
S5 & Nonmetal material products \\
S6 & Textile industry \\
S7 & Smelting and pressing of ferrous metals \\
S8 & Telecommunication computer, equipment and other electronic equipment manufacturing \\
S9 & Electric machinery and equipment \\
S10 & Wine, beverage, and refined tea production \\
\hline
\end{tabular}

\section{Market Share}

The market shares of nonmetal material products and smelting and pressing of nonferrous metals in central six provinces account for one third of total shares in China, which are dominant sectors in these provinces. The market advantages of Hubei province focus on motor manufacturing, wine, beverage, and refined tea production. The market advantage of Henan province focuses on food processing, raw chemical material, chemical products, nonmetal material products, textile industry, smelting and pressing of ferrous metals, telecommunication computer, equipment and other electronic equipment manufacturing. Jiangxi province puts more emphasis on smelting and pressing of nonferrous metals. The electronic machinery and equipment sector of Anhui province obtains more market shares than other provinces in the central China (Table 3). So the market advantage of Hubei province mainly is concentrated on traditional manufacturing.

Table 3

Market Share (\%)

\begin{tabular}{lllllllll}
\hline Sectors & Hubei & Hunan & Shanxi & Henan & Jiangxi & Anhui & 6 Provinces & China \\
\hline S1 & 42.39 & 9.57 & 0.67 & 21.04 & 9.03 & 17.31 & 100 & 18.57 \\
S2 & 24.22 & 15.85 & 1.71 & 32.25 & 10.42 & 15.56 & 100 & 28.50 \\
S3 & 25.19 & 17.81 & 4.06 & 25.42 & 14.45 & 13.07 & 100 & 19.16 \\
S4 & 15.05 & 13.99 & 1.64 & 44.07 & 13.57 & 11.68 & 100 & 33.22 \\
S5 & 28.77 & 8.21 & 0.49 & 34.53 & 14.95 & 13.04 & 100 & 18.72 \\
S6 & 17.01 & 11.42 & 16.11 & 28.70 & 10.43 & 16.33 & 100 & 19.10 \\
S7 & 17.19 & 16.24 & 5.74 & 31.92 & 11.83 & 17.08 & 100 & 12.46 \\
S8 & 12.37 & 12.38 & 0.95 & 22.19 & 19.77 & 32.34 & 100 & 19.87 \\
S9 & 33.36 & 13.06 & 4.08 & 30.21 & 6.66 & 12.63 & 100 & 28.21 \\
S10 & 8.01 & 14.78 & 3.08 & 26.77 & 32.43 & 14.91 & 100 & 36.49
\end{tabular}

\section{Total Assets Contribution Rate}

The profitability of individual sectors is different. The profitability of same sectors in different provinces is different, too (Table 4). Food processing, textile industry, and wine, beverage, and refined tea production can get higher total assets contribution rates, which are all traditional industries. The total assets contribution rates of raw chemical material and chemical products, nonmetal material products, electric machinery and equipment, and smelting and pressing of nonferrous metals are of medium level. The assets contribution rates of 
manufacturing, telecommunication computer, equipment, and other electronic equipment manufacturing and smelting and pressing of ferrous metals are of low level, some of which are technology-intensive sectors.

For the same sectors, Jiangxi province obtains the highest total assets contribution rates in eight sectors including food processing, raw chemical material and chemical products, textile industry, smelting and pressing of ferrous metals, telecommunication computer, equipment and other electronic equipment manufacturing, electric machinery and equipment, wine, beverage, and refined tea production, and smelting and pressing of nonferrous metals. Hubei is only able to make more profits in motor manufacturing and Hunan has highest profitability in nonmetal material products.

Table 4

Total Assets Contribution Rate (\%)

\begin{tabular}{lllllll}
\hline Sectors & Hubei & Hunan & Shanxi & Henan & Jiangxi & Anhui \\
\hline S1 & 16 & 8.3 & 2.1 & 14.7 & 4.4 & 9.2 \\
S2 & 20.1 & 22.7 & 9.6 & 17.8 & 40 & 16.7 \\
S3 & 11.9 & 24.6 & 1.3 & 17.9 & 29.9 & 11.6 \\
S4 & 17 & 18.7 & 2 & 11 & 13.5 & 11.8 \\
S5 & 21.3 & 15.3 & 2.8 & 15.5 & 47.2 & 13.2 \\
S6 & 0.5 & 7.8 & 0.1 & 6.9 & 22.9 & 5.5 \\
S7 & 5.7 & 17.7 & 8.7 & 6.4 & 21.6 & 8.2 \\
S8 & 12.6 & 11.4 & 5 & 15.3 & 25.8 & 16.1 \\
S9 & 17.8 & 20.3 & 13.3 & 15 & 93.2 & 23.9 \\
S10 & 3.5 & 13.6 & 5.9 & 15.7 & 35.9 & 4.6 \\
\hline
\end{tabular}

\section{Main Business Revenue Growth Rate}

Compared with the main business revenue of these 10 sectors in 2014, the indicators increased in 2015 except smelting and pressing of ferrous metals (Table 5). Henan province obtained the highest growth rate in most sectors including motor manufacturing, smelting and pressing of ferrous metals, telecommunication computer, equipment and other electronic equipment manufacturing, raw chemical material and chemical products, and nonmetal material products. Hunan province got highest main business revenue growth rate in food processing and electric machinery and equipment. The textile industry in Jiangxi province and the smelting and pressing of nonferrous metals in Anhui province increased a lot. The wine, beverage, and refined tea production in Hubei developed faster than this sector in other five provinces.

Table 5

Main Business Revenue Growth Rate (\%)

\begin{tabular}{lllllll}
\hline Sectors & Hubei & Hunan & Shanxi & Henan & Jiangxi & Anhui \\
\hline S1 & 108.65 & 114.72 & 93.58 & 118.15 & 109.74 & 114.23 \\
S2 & 105.43 & 113.60 & 89.22 & 107.56 & 113.54 & 105.30 \\
S3 & 106.34 & 103.49 & 84.45 & 107.64 & 104.22 & 104.22 \\
S4 & 104.80 & 107.67 & 86.74 & 111.56 & 107.43 & 105.69 \\
S5 & 102.07 & 104.39 & 8.87 & 104.65 & 112.63 & 107.98 \\
S6 & 77.89 & 86.22 & 67.00 & 92.03 & 88.45 & 84.08 \\
S7 & 122.15 & 114.94 & 110.62 & 125.71 & 117.11 & 122.38 \\
S8 & 104.72 & 119.20 & 101.29 & 112.48 & 114.28 & 106.86 \\
S9 & 115.78 & 115.72 & 102.06 & 106.16 & 105.12 & 107.19 \\
S10 & 99.83 & 101.21 & 101.65 & 105.52 & 98.71 & 106.86 \\
\hline
\end{tabular}




\section{Location Quotient}

Each of the six provinces has own location advantage sectors, such as telecommunication computer, equipment and other electronic equipment manufacturing, and smelting and pressing of ferrous metals in Shanxi province, nonmetal material products in Henan province, smelting and pressing of nonferrous metals in Jiangxi province, electric machinery and equipment in Anhui province, motor manufacturing, food processing, wine, beverage, and refined tea production, textile industry, and raw chemical material and chemical products in Hubei province (Table 6). The location advantage sectors in Shanxi province are mainly concentrated on resource-intensive sectors and the ones in Hubei province are mainly concentrated on labor-intensive and capital-intensive sectors, which call for more technological innovations to change.

Table 6

\section{Location Quotient}

\begin{tabular}{lllllll}
\hline Sectors & Hubei & Hunan & Shanxi & Henan & Jiangxi & Anhui \\
\hline S1 & 2.24 & 0.58 & 0.21 & 0.68 & 0.64 & 1.06 \\
S2 & 1.28 & 0.95 & 0.53 & 1.05 & 0.74 & 0.95 \\
S3 & 1.33 & 1.07 & 1.26 & 0.83 & 1.02 & 0.80 \\
S4 & 0.80 & 0.84 & 0.51 & 1.43 & 0.96 & 0.71 \\
S5 & 1.52 & 0.49 & 0.15 & 1.12 & 1.06 & 0.80 \\
S6 & 0.90 & 0.69 & 5.01 & 0.93 & 0.74 & 1.00 \\
S7 & 0.91 & 0.98 & 1.78 & 1.04 & 0.84 & 1.04 \\
S8 & 0.65 & 0.74 & 0.30 & 0.72 & 1.40 & 1.98 \\
S9 & 1.76 & 0.79 & 1.27 & 0.98 & 0.47 & 0.77 \\
S10 & 0.42 & 0.89 & 0.96 & 0.87 & 2.30 & 0.91 \\
\hline
\end{tabular}

\section{Indicator of Industrial Competitiveness}

After multiplying the above four variables, we have an indicator of industrial competitiveness (Table 7).

Table 7

Indicator of Industrial Competitiveness

\begin{tabular}{lllllll}
\hline Sectors & Hubei & Hunan & Shanxi & Henan & Jiangxi & Anhui \\
\hline S1 & 165,174 & 5,242 & 28 & 24,978 & 2,789 & 19,235 \\
S2 & 65,726 & 38,972 & 774 & 64,729 & 34,898 & 26,014 \\
S3 & 42,461 & 48,582 & 564 & 40,456 & 46,074 & 12,619 \\
S4 & 21,347 & 23,695 & 146 & 77,458 & 18,910 & 10,399 \\
S5 & 95,164 & 6,479 & 2 & 62,845 & 84,212 & 14,816 \\
S6 & 596 & 5,278 & 541 & 16,999 & 15,607 & 7,537 \\
S7 & 10,879 & 32,272 & 9,846 & 26,638 & 25,099 & 17,895 \\
S8 & 10,677 & 12,525 & 143 & 27,543 & 81,608 & 109,965 \\
S9 & 121,269 & 24,118 & 7,040 & 47,224 & 30,764 & 24,964 \\
S10 & 1,187 & 18,097 & 1,770 & 38,600 & 264,080 & 6,680 \\
\hline
\end{tabular}

\section{Conclusion}

This paper investigates the advantage sectors' influence on manufacturing competitiveness using the data of Hubei, Hunan, Shanxi, Henan, Jiangxi, and Anhui provinces between 2014 and 2015. We measure the comprehensive advantage industrial competitiveness of 10 sectors of these six central China provinces. We offer basic conclusions and their policy implications below. 
To analyze the industrial competitiveness of six provinces, we choose the top three of every sector and find the most competitive sectors of every province.

The most competitive sectors of Hubei province are motor manufacturing, food processing, raw chemical material and chemical products, nonmetal material products, textile industry, and wine, beverage, and refined tea production.

The most competitive sectors of Hunan province are food processing, raw chemical material and chemical products, nonmetal material products, telecommunication computer, equipment and other electronic equipment manufacturing, and smelting and pressing of nonferrous metals.

The most competitive sectors of Henan province are motor manufacturing, food processing, nonmetal material products, textile industry, smelting and pressing of ferrous metals, telecommunication computer, equipment and other electronic equipment manufacturing, electric machinery and equipment, wine, beverage, and refined tea production, and smelting and pressing of nonferrous metals.

The most competitive sectors of Jiangxi province are raw chemical material and chemical products, textile industry, smelting and pressing of ferrous metals, telecommunication computer, equipment and other electronic equipment manufacturing, electric machinery and equipment, wine, beverage, and refined tea production, and smelting and pressing of nonferrous metals.

The most competitive sectors of Anhui province are motor manufacturing, smelting and pressing of ferrous metals, and electric machinery and equipment.

Shanxi province has no relatively competitive sectors due to the lagging of the industrial structure adjustment and development limits of resource-intensive industrial.

\section{References}

Anhui Bureau of Statistics. (2015). Anhui Statistical Yearbook 2015, Hefei.

Anhui Bureau of Statistics. (2016). Anhui Statistical Yearbook 2016, Hefei.

Hubei Bureau of Statistics. (2015). Hubei Statistical Yearbook 2015, Wuhan.

Hubei Bureau of Statistics. (2016). Hubei Statistical Yearbook 2016, Wuhan.

Hunan Bureau of Statistics. (2015). Hunan Statistical Yearbook 2015, Changsha.

Hunan Bureau of Statistics. (2016). Hunan Statistical Yearbook 2016, Changsha.

Henan Bureau of Statistics. (2015). Henan Statistical Yearbook 2015, Zhengzhou.

Henan Bureau of Statistics. (2016). Henan Statistical Yearbook 2016, Zhengzhou.

Jiangxi Bureau of Statistics. (2015). Jiangxi Statistical Yearbook 2015, Nanchang.

Jiangxi Bureau of Statistics. (2016). Jiangxi Statistical Yearbook 2016, Nanchang.

National Bureau of Statistics of the People’s Republic of China. (2015). China Statistical Yearbook 2014, Beijing.

Porter, M. E. (1985). Competitive advantage. New York: Free Press.

Ricardo, D. (1817). On the principles of political economy and taxation. London: John Murray.

Smith, A. (1776). An inquiry into the nature and causes of the wealth of nations. London: W. Strahan and T. Cadell.

Sun, Y., \& Du, D. (2010). Determinants of industrial innovation in China: Evidence from its recent economic census. Technovation, 30, 540-550.

Shanxi Bureau of Statistics. (2015). Shanxi Statistical Yearbook 2015, Taiyuan.

Shanxi Bureau of Statistics. (2016). Shanxi Statistical Yearbook 2016, Taiyuan. 